\title{
The 2D Finite Element Microstructure Evaluation of V-Shaped Arc Welding of AISI 1045 Steel
}

\author{
Omer Eyercioglu ${ }^{1, *}$, Ahmed Samir Anwar ${ }^{2}$, Kursat Gov ${ }^{3}$ and Necip Fazil Yilmaz ${ }^{4}$ \\ 1 Department of Mechanical Engineering, Gaziantep University, Gaziantep 27310, Turkey \\ 2 Department of Mechanical Engineering, Salahaddin University, Erbil 44001, Iraq; eyeroglu@gmail.com \\ 3 Department of Aeronautics and Astronautics Engineering, Gaziantep University, Gaziantep 27310, Turkey; \\ gov@gantep.edu.tr \\ 4 Department of Mechanical Engineering, Gaziantep University, Gaziantep 27310, Turkey; \\ nfyilmaz@gantep.edu.tr \\ * Correspondence: eyercioglu@gantep.edu.tr; Tel.: +90-342-3601200
}

Academic Editors: Halil Ibrahim Kurt, Adem Kurt and Necip Fazil Yilmaz

Received: 28 November 2016; Accepted: 1 February 2017; Published: 3 February 2017

\begin{abstract}
In the present study, V-shaped arc welding of the AISI 1045 steel is modeled by using 2D Finite Element Model (FEM). The temperature distribution, microstructure, grain growth, and the hardness of the heat-affected zone (HAZ) of the welding are simulated. The experimental work is carried out to validate the FE model. The very close agreement between the simulation and experimental results show that the FE model is very effective for predicting the microstructure, the phase transformation, the grain growth and the hardness. The effect of preheat temperature on the martensite formation is analysed, and it is shown that $225^{\circ} \mathrm{C}$ preheating completely eliminates the martensite formations for the $12 \mathrm{~mm}$ thick plate.
\end{abstract}

Keywords: arc welding; AISI 1045 steel; DEFORM ${ }^{\mathrm{TM}}$ FE; pre-heating; HAZ; microstructure

\section{Introduction}

AISI 1045 steel is a medium carbon steel that is used for a wide range of engineering applications such as structural works, machine parts, gears studs, axels, cold extrude, etc. Thus, in most cases, parts are welded together to form permanent joints, but, unfortunately, due to its carbon content, the martensite phase is liable to form in the heat affected zone (HAZ) and may cause brittle fracture of the joint.

A lot of researchers have explored the theoretical and experimental works to conclude the effects of welding parameters (the welding process type that was employed, welding current, voltage, and the arc travelling speed, etc.) on the quality of the weldment. Modelling and simulation is becoming very useful in welding analysis and is preferred for reducing cost and time consumption of experiments [1]. Because of the complexity of the problem, the experimental work is required at a minimum to validate the simulation results. By the progress of the software technology now, it is possible to use numerical techniques like the Finite Element Method (FEM). Sattari-Far and Farahani have used FEM to analyze the thermo mechanical behavior and residual stress in butt welded pipes of 6 and $10 \mathrm{~mm}$ thickness of different groove shapes. They stated that welding parameter has a significant effect on the magnitude and distribution of the residual stress in butt weld pipes [2].

Barsoum and Lundbäck studied two- and three-dimensional welding simulations by using MSC-Marc and ANSYS finite element packages for the T-type fillet weld. They concluded that the prediction of the residual stress on the 2D package shows suitable and good agreement for the welding process [3]. Tsai et al. presented numerical modelling for analysis of the heat treatment on the properties of the magnesium alloy in Tungsten inert gas (TIG) welding. They found that increasing the 
time and temperature of tempering led to high tensile strength and elongation [4]. Unfried, Garzon, and Giraldo represented evaluation of the microstructure after arc welding for the armor steel plate. The approach to the reliability is approved by using the case study methodology. The comparison is also carried out between the experimental work and the modelling for the microstructure evaluation and micro-hardness on the MIL A46100 armor steel plates (low alloy steel) welded by AWS E11018M covered electrode [5]. Zhang et al. modeled the temperature and residual stress due to the welding process on Cr5Mo steel tube by using an ABAQUS package. They noticed that welding residual stress is very large at the beginning stage and it then becomes relaxed in a short time at a high temperature [6].

In this study, V-shaped butt welding of AISI 1045 steel is simulated by the FEM using the DEFORM $^{\mathrm{TM}}$ package. The microstructure evaluation of the AISI 1045 steel during two-pass arc welding is modeled by using 2D FEM. The effect of pre-heating on the martensite formation is also analyzed. The experimental work was carried out to validate the results.

\section{The FE Modelling}

The V-shaped butt welding model is prepared from $12 \mathrm{~mm}$ thick AISI 1045 steel plate. The 2D FEM model is used according to the results of Ref [3]. The geometry of the V-groove is selected according to ISO 9692 standard [7] as shown in Figure 1. The welding simulation is carried out in two successive passes and the welding pool is taken as a heat source. The heat transfer through parent metal is analyzed by time for heating (welding) and cooling stages. The deformation, heat transfer, phase transformation, and diffusion are coupled with each other in DEFORMTM simulations. For example, for carbon steel, the material properties are functions of the carbon content. As the concentration of carbon may be changed by diffusion, the mechanical and thermal properties of the steel will change accordingly.

Elasto-Plastic mechanical analysis and the Newton-Raphson iteration solution method have been selected. The material properties of the AISI 1045 steel are taken according to [8,9]. The thermal conductivity has been defined as a function of temperature. The environmental temperature is taken as $20^{\circ} \mathrm{C}$ and the welding and cooling is taken place at the environment temperature. The maximum temperature during welding is $1400^{\circ} \mathrm{C}$ and it is defined in the FE model. Due to the symmetry of the geometry, one-half of the shape is modeled and meshed to 3000 4-node 2D plane elements.

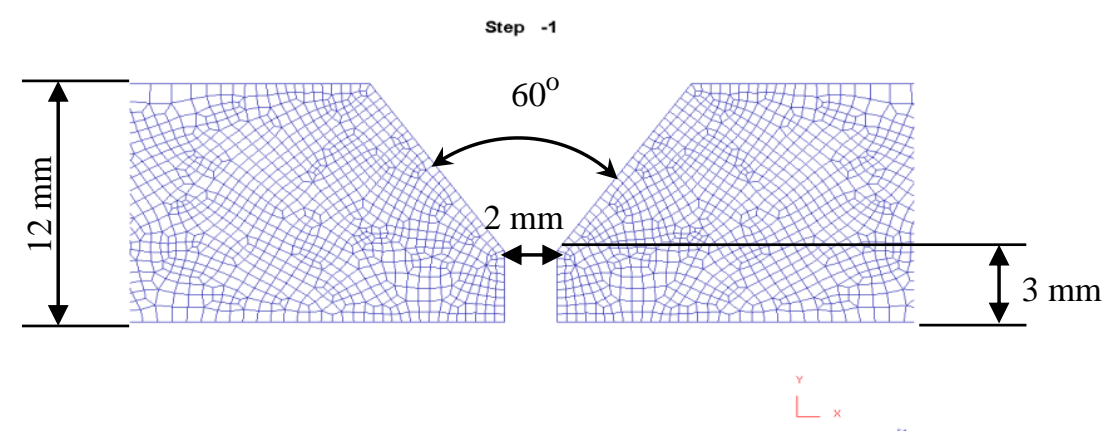

Figure 1. Dimensions of the V-shape welding groove according to ISO 9692 [7].

The flow stress of the material is defined as a function of effective (true) strain and temperature as shown in Figure 2. 


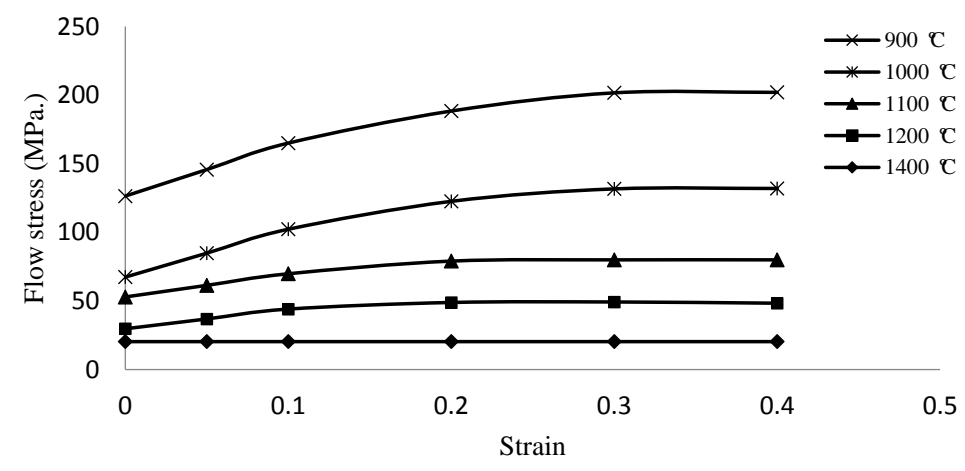

Figure 2. The flow stress and temperature as a function of effective (true) strain.

The thermal conductivity data of the AISI 1045 steel [8] have been defined as shown in Figure 3.

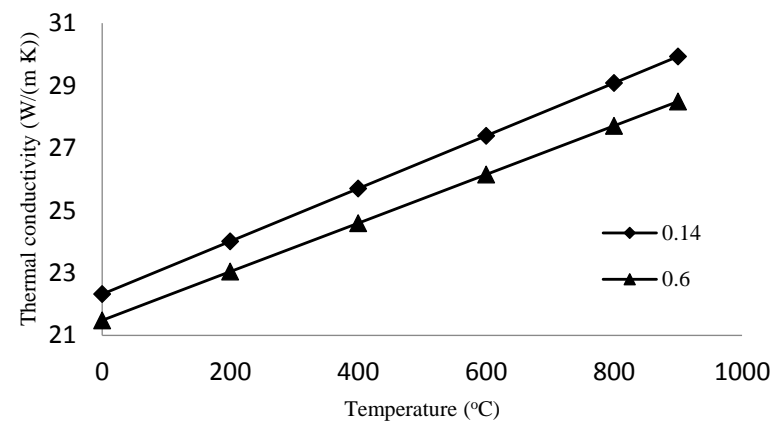

Figure 3. Thermal conductivity of the AISI 1045 steel with respect to the temperature for atom contents (here is the carbon content) of 0.14 and 0.6 percent.

For the phase transformation and the microstructure evaluation in the DEFORM ${ }^{\mathrm{TM}} 2 \mathrm{D}$, it is necessary to define all of the phases (austenite, bainite and martensite). The phases for the AISI 1045 steel have been defined and the phase transformation of the material was determined by the volumetric weighting of each phase. The transformation of one phase to another is defined as a mother and child relationship [8-10]. The time temperature transformation (TTT) diagram of AISI 1045 steel has been defined as shown in Figure 4.

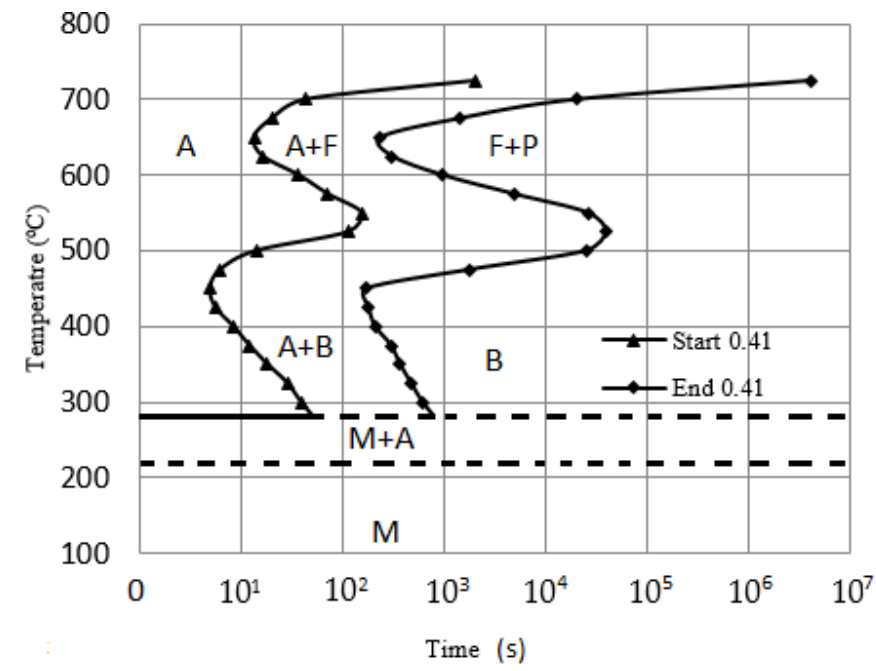

Figure 4. Time Temperature Transformation (TTT) diagram of AISI 1045 steel [9]. 
The Avrami equation was used for solving volume fraction and transformation which is playing an important role in the transformation process and grain size. This is shown in Figure 5, which has the following form:

$$
\xi=1-\exp \left(-k t^{n}\right)
$$

where $\xi$ is the volume fraction transformed, $t$ is the time, and $k$ and $n$ are constants ( $n$ being the Avrami number). In terms of TTT data, two curves (i.e., transformation start and transformation finish curves) are required in order to solve for $k$ and $n$. If only one curve is input to DEFORM ${ }^{\mathrm{TM}}$ (Scientific Forming Technologies Corporation, Columbus, OH, USA), the Avrami number has to be defined. For the grain modeling, the grain size, the peak strain and the strain rate boundary are defined as a function of the temperature in the DEFORM ${ }^{\mathrm{TM}}$ heat treatment lab.

The hardness distribution in the model was estimated based on the Jominy curve by computing the cooling rate for each element [8]. The Jominy curve, hardness as a function of distance, is shown in Figure 6.

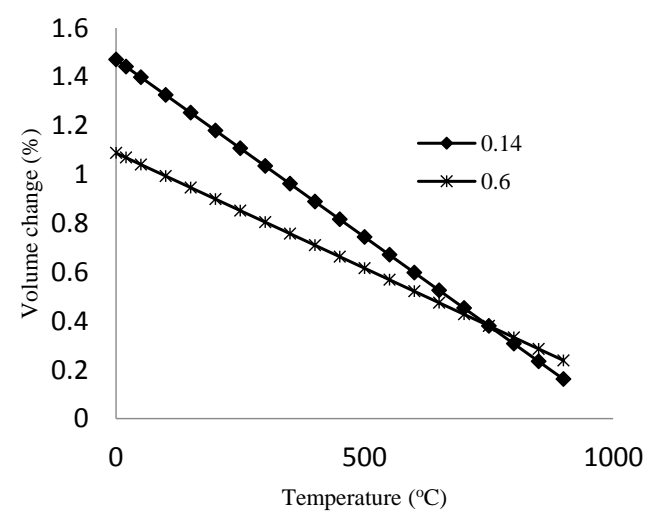

Figure 5. Volume fraction in percent and transformation per temperature for AISI 1045 steel according to 0.14 and 0.6 carbon content $[8,10]$.

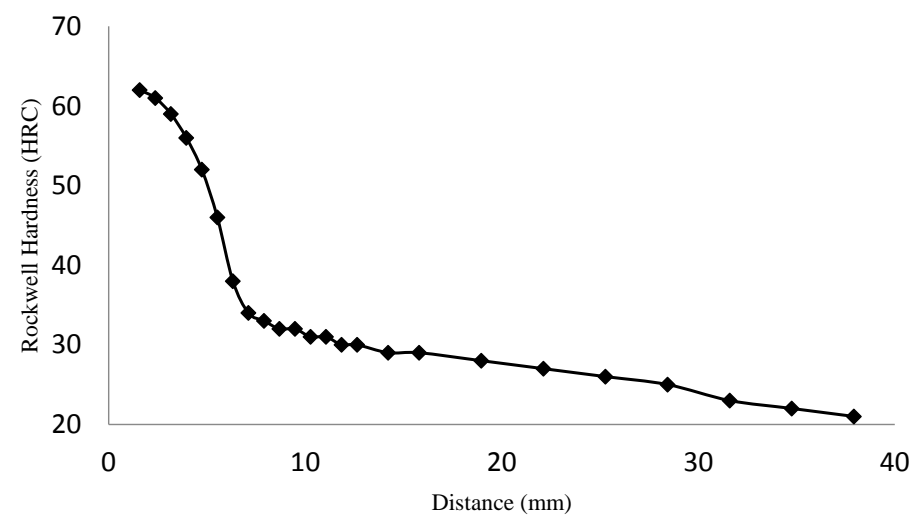

Figure 6. Jominy test by Rockwell hardness, as a function of distance for AISI 1045 steel [8].

\section{Materials and Methods}

The main purpose of the experimental work is to validate the results of the finite element model. For this reason, a $12 \mathrm{~mm}$ thick AISI 1045 steel plate was taken. The chemical composition of the material was analyzed by using a SPECTROMAX 3x metal spectrometer (Spectromax Solutions Ltd, London, UK) and the results are given in Table 1. According to the specification given in the ISO 9692 standard, a V-shaped weld groove was prepared. In the shielded metal arc welding process, depending on the type and the thickness of the material, the specifications such as number of passes, electrode 
size and type, current and welding speed have to be taken into account. The welding process was carried out for $0.1 \mathrm{~cm} / \mathrm{s}$ welding speed; $5 \mathrm{~mm}$ diameter E7018 electrode and 200 A current. The welded specimen was prepared according to ASTM E3 for metallographic inspection [11]. The macro- and micro-structural features of HAZ of the welding were investigated by using an $8 \mathrm{HD}$ mega-pixel digital cameras and a compound optical metallurgical microscope (equipped with 5 mega-pixel eyepiece digital cameras) that is connected to the PC. Grain size measurements of the HAZ and the base metal for welded joint were done by using the linear intercept method as it is specified in ASTM E112 [12]. After that, the welded parts were sliced and then the pieces were machined to the required size to prepare the sample for micro-hardness testing, which was conducted according to ASTM E92-03 [13]. The micro-hardness measurements were taken as $3 \mathrm{~mm}, 6 \mathrm{~mm}$ and $9 \mathrm{~mm}$ above the weld root of the specimen perpendicular to the welding direction using a diamond pyramid indenter.

Table 1. Chemical composition of AISI 1045.

\begin{tabular}{cccccccccc}
\hline Element & $\mathbf{C} \%$ & Fe \% & Mn \% & P \% & Si \% & Cu \% & Cr \% & Ti \% & S \% \\
\hline Percentage & 0.41 & 98.31 & 0.849 & 0.0005 & 0.161 & 0.0119 & 0.0323 & 0.0005 & 0.008 \\
\hline
\end{tabular}

\section{Experimental Work}

\subsection{Microstructure and Grain Size}

During welding, the molten pool moves through the material, the growth rate and temperature gradient varies considerably across the weld pool. This situation has a significant effect on the phase transformation changes and the average grain size growth in the HAZ area. A transverse macro-section through the HAZ of AISI 1045 steel in the microstructure shows that the average grain sizes are adjacent to the fusion line is large. Meanwhile, the temperature increase in the HAZ triggers the martensite phase formation during cooling. The chemical composition of the medium carbon steel makes significant changes in the curve shape of the Time Temperature Transformation (TTT) diagram and the phase transformation time of the steel. In our case, (AISI 1045 steel), martensite phase transformation has been seen at the different points in the HAZ area during the normal air cooling process. Grain growth and the formation of the martensite phase can cause surface cracking, which is clearly shown in Figure 7. The average grain size distribution found in the finite element model is shown in Figure 8. From the results of the grain size investigation of the AISI 1045 steel, it is found that the grain size of the FE model at the adjacent point to the fusion line for the welding was $1258 \mu \mathrm{m}$, whereas the experimental result was $1200 \mu \mathrm{m}$. Similar results were obtained for different regions of HAZ of the welding as shown in Figure 9. Therefore, there is good agreement between the experimental and simulation results.
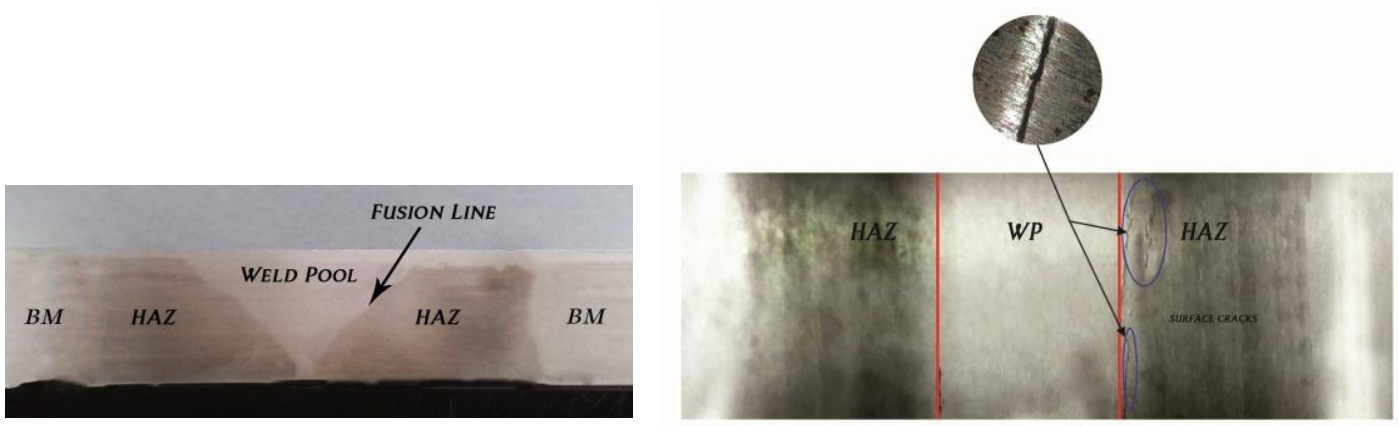

Figure 7. The effect of the shielded metal arc welding on the Heat Affected Zone (HAZ) area and surface crack formation after the welding process for AISI 1045. 


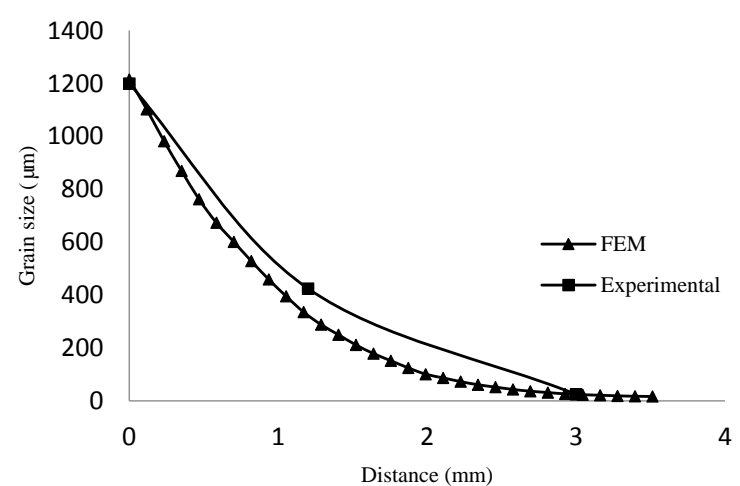

Figure 8. Average grain size taken from adjacent to fusion line through HAZ for AISI 1045 steel.

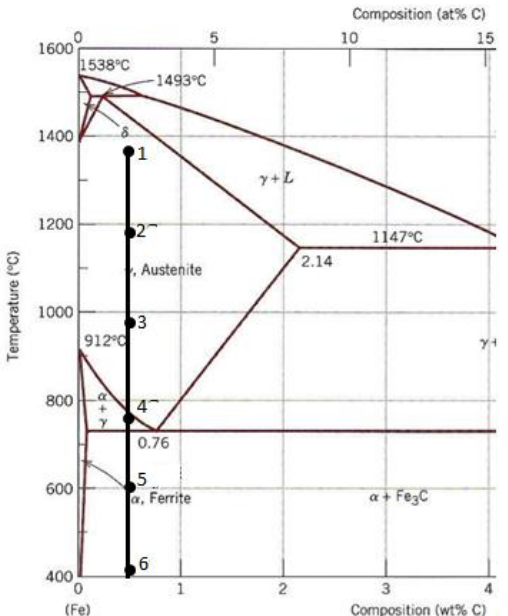

(a)

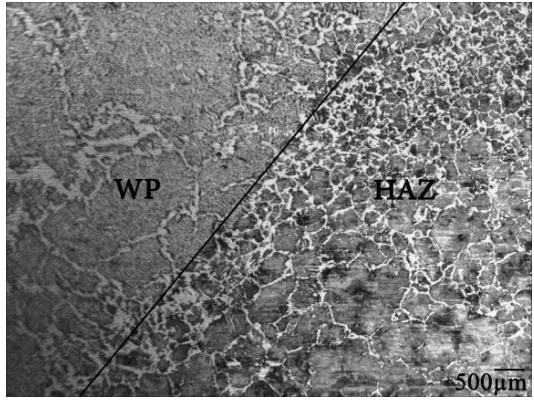

(d)

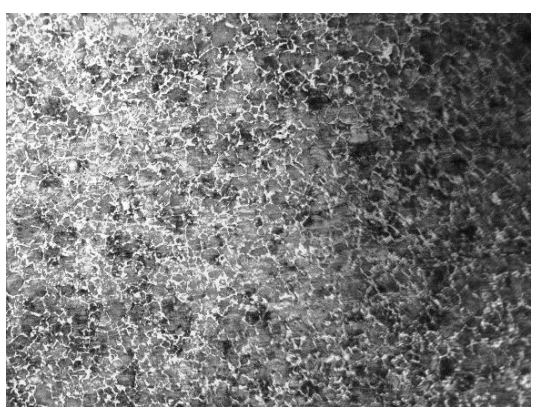

(f)

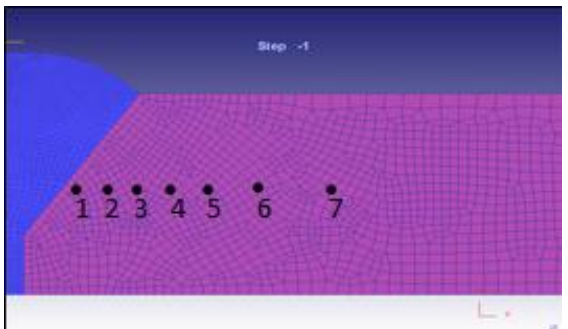

(b)

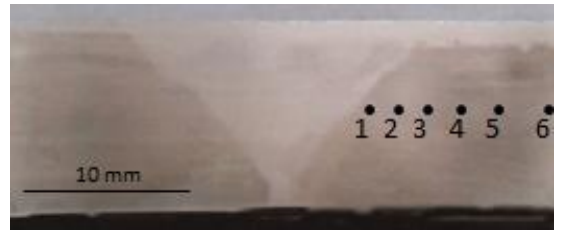

(c)

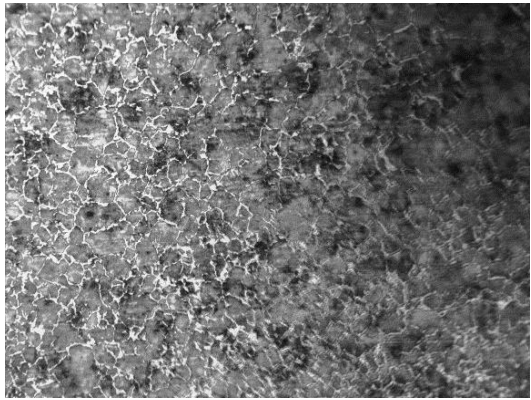

(e)

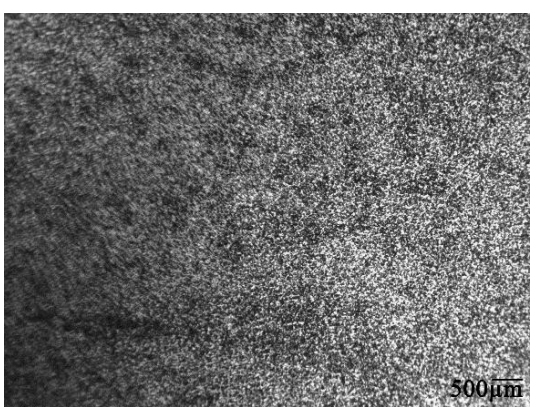

(g)

Figure 9. (a) Fe-C diagram (b) Finite element model (c) macrograph, and microstructures around (d) point 1 (e) point 2 (f) point 3 (g) point 4 on the transverse section of the welded AISI 1045 steel. 
On the other hand, it is possible to investigate the temperature distribution in HAZ of the prepared model during welding and the cooling simulations, which are beneficial for the extraction of the microstructure of the selected points. The recorded temperature distribution of the finite element model is shown in Figure 10.

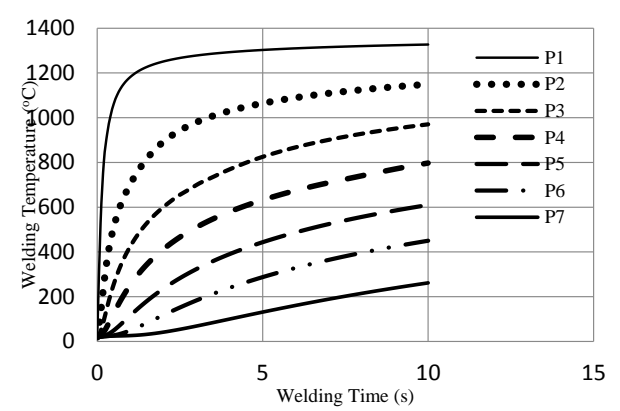

(a)

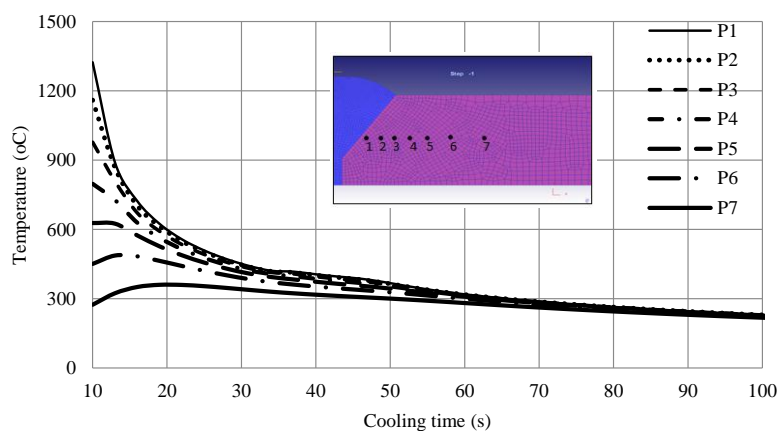

(b)

Figure 10. Temperature distribution of the HAZ region of the finite element model during (a) welding time and (b) cooling in still air.
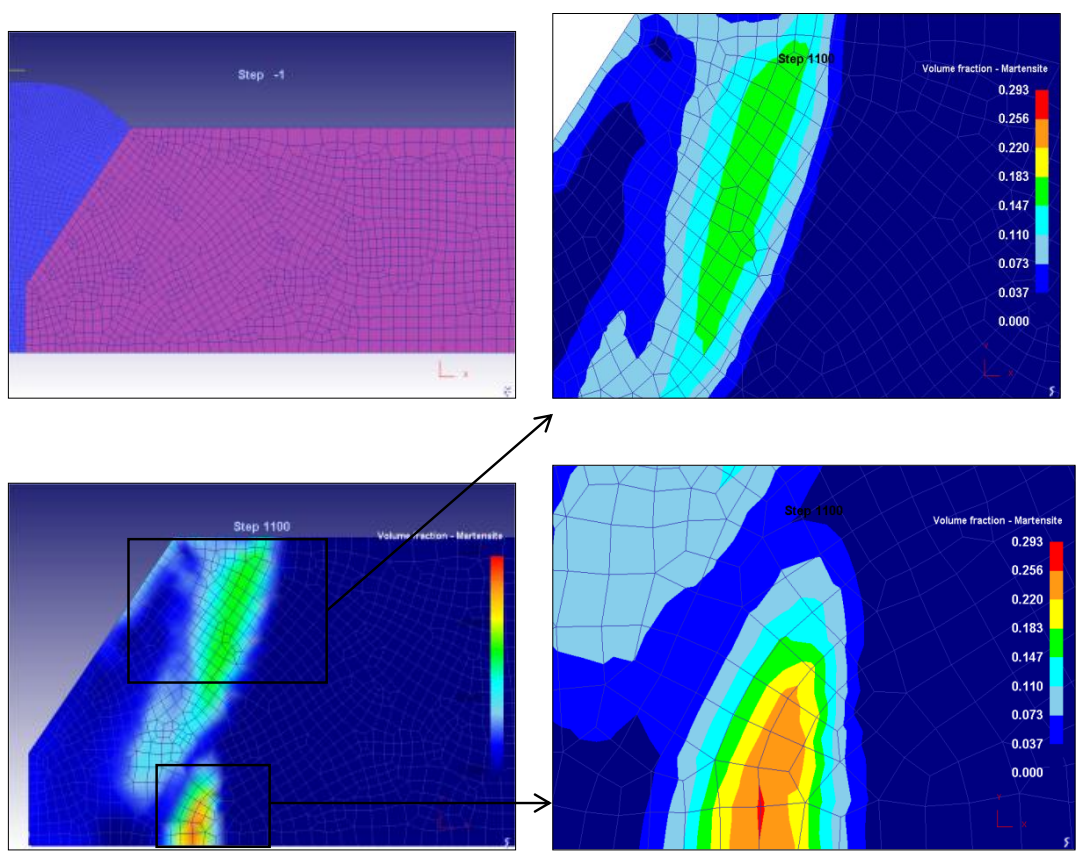

Figure 11. Volume fraction of martensite of HAZ after cooling to room temperature. 
The microstructural evolution of the HAZ was determined by the FE model based on the TTT diagram and the cooling curves given in Figure 10. The formation of the martensite phase has been noticed at room temperature as is shown in Figure 11 during cooling stages in normal exposed air cooling processes. The maximum volume fractions of martensite are 0.256 in regions in Figure 11.

\subsection{Hardness Test}

The hardness distribution of the FE model perpendicular to the welding direction is given in Figure 12. The hardness values were taken as $3 \mathrm{~mm}, 6 \mathrm{~mm}$ and $9 \mathrm{~mm}$ above the weld root. The micro-hardness measurements were done on the same area of the specimen and are plotted in Figure 12. The micro-hardness measurements were converted to Rockwell $C$ for comparison. The results show that the FE model and the experimental measurements are in good agreement. The maximum difference between the experimental and FE model is lower than 2 HRC.

\subsection{Preheating Process}

Preheating processes were investigated to eliminate the martensite formation. The preheating temperatures were increased gradually starting from $100{ }^{\circ} \mathrm{C}$, and, for $225{ }^{\circ} \mathrm{C}$, the formation of martensite was totally eliminated. The resulting simulation of martensite formation is given in Figure 13.

From Figure 13, the maximum volume fractions of martensite were 0.195 and 0.0079 for $100{ }^{\circ} \mathrm{C}$ and $200{ }^{\circ} \mathrm{C}$ preheating temperatures, respectively. It was found that no martensite was formed for $225{ }^{\circ} \mathrm{C}$ preheating temperature. The hardness and the average grain size distribution adjacent to the fusion line, $6 \mathrm{~mm}$ above the weld root in the HAZ region, are plotted in Figures 14 and 15 at different preheating temperatures. From Figure 14, the maximum hardness was found as $34.21 \mathrm{HRC}$ for no preheating, and they were $31.95 \mathrm{HRC}, 30.2 \mathrm{HRC}$ and $30 \mathrm{HRC}$ for the $100{ }^{\circ} \mathrm{C}, 200^{\circ} \mathrm{C}$ and $225^{\circ} \mathrm{C}$ preheating temperatures, respectively. In Figure 15, the peak grain size for the no preheating condition was $1258 \mu \mathrm{m}$ and gradually reduced with increasing preheating temperature: $900 \mu \mathrm{m}$ for $100{ }^{\circ} \mathrm{C}$, $738 \mu \mathrm{m}$ for $200{ }^{\circ} \mathrm{C}$ and $447 \mu \mathrm{m}$ for $225^{\circ} \mathrm{C}$. According to the FE results, it is clear now to say that the $225^{\circ} \mathrm{C}$ preheating process for the $12 \mathrm{~mm}$ thick, V-shape groove AISI 1045 steel can be recommended to prevent martensite formation.
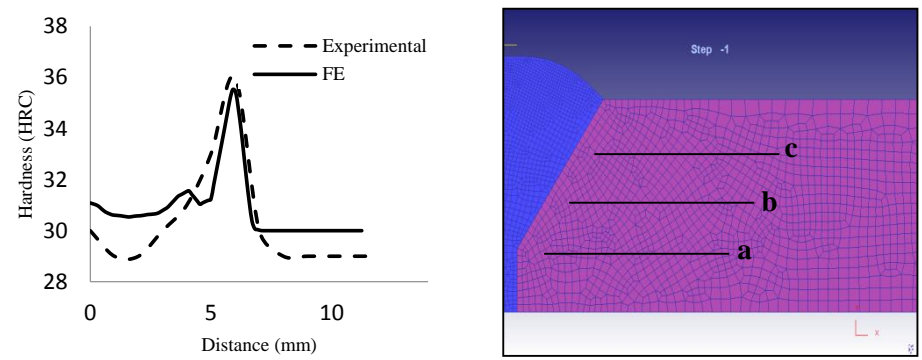

(a)

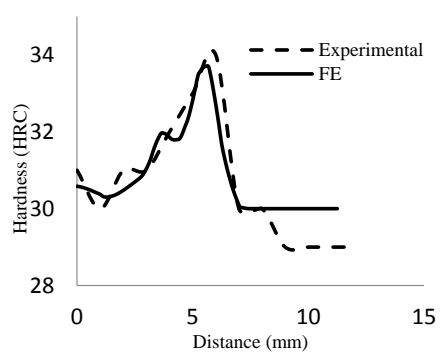

(b)

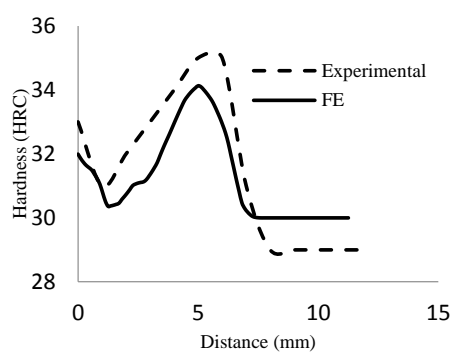

(c)

Figure 12. Distribution of hardness for (a) $3 \mathrm{~mm}$, (b) $6 \mathrm{~mm}$ and (c) $9 \mathrm{~mm}$ above the weld root through the HAZ. 

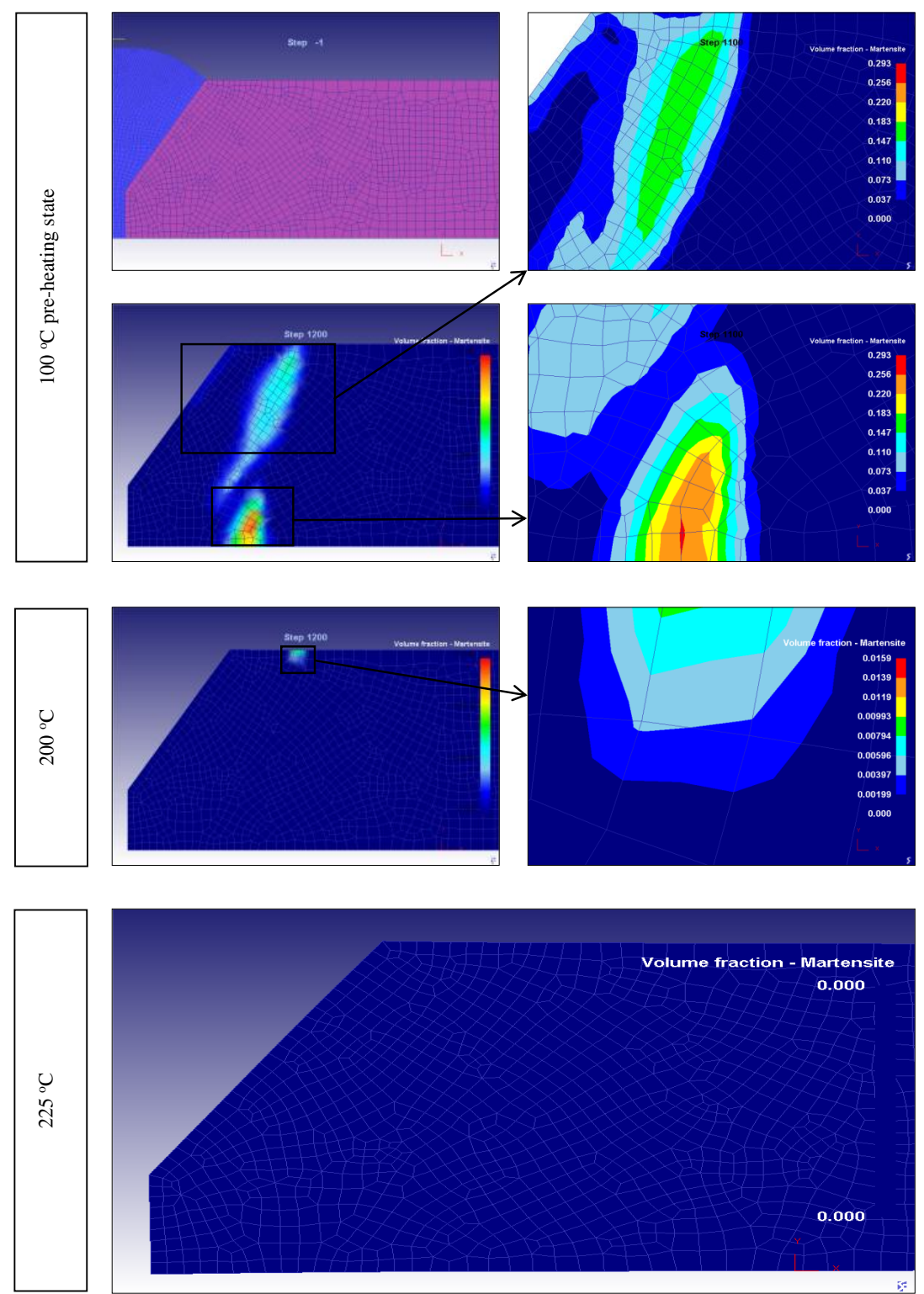

Figure 13. Elimination of martensite formation phase transformation of the AISI 1045 steel for different pre-heating temperatures.

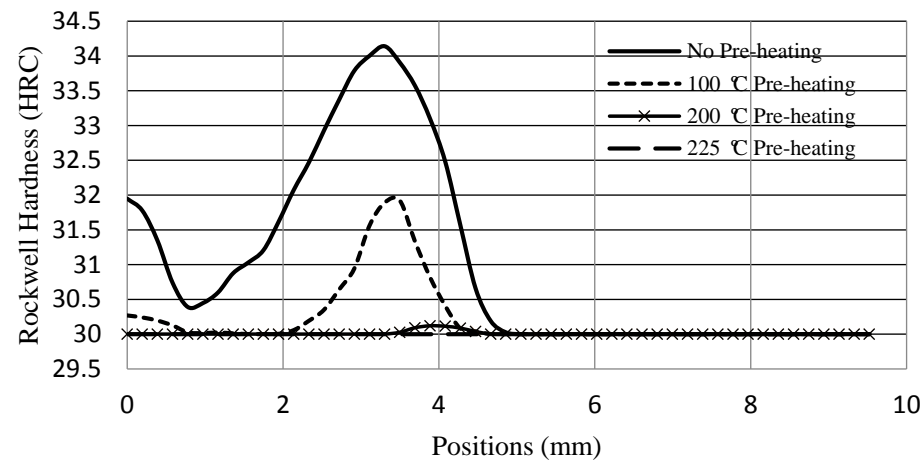

Figure 14. Distribution of hardness at the mid transverse direction of the welding line through the HAZ for different states of preheating. 


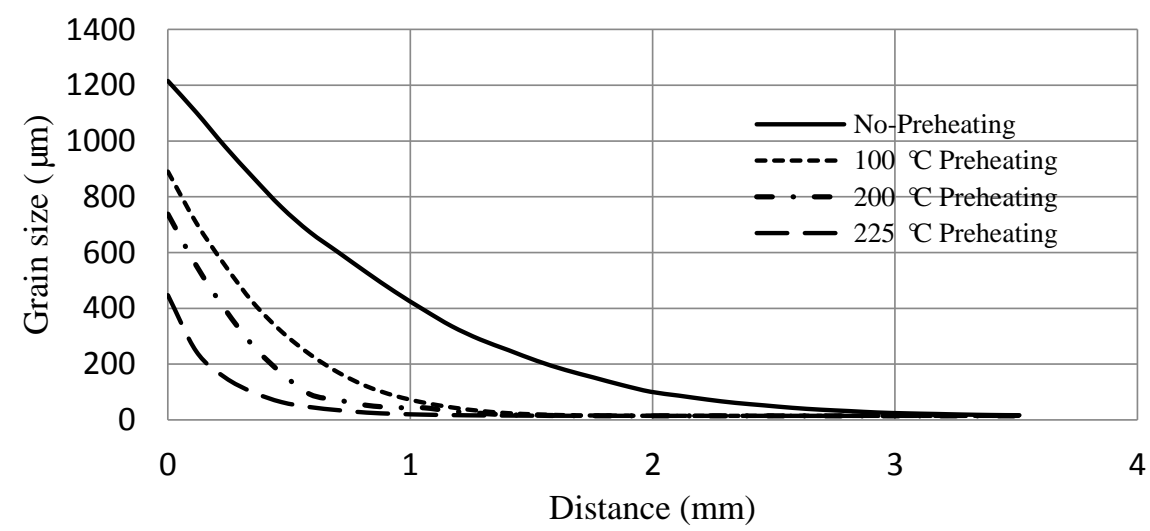

Figure 15. Distribution of average grain size at the mid transverse direction of the welding line through the HAZ for different states of preheating.

\section{Conclusions}

In this study, the 2D finite element model of V-shaped butt welding of AISI 1045 steel is presented. The temperature distribution, microstructure, grain growth, and the hardness of the heat affected zone (HAZ) were simulated. The results of simulation were compared with the experimental ones. According to the results obtained in the study, the following may be concluded:

1. The very close agreement between the simulation and experimental results show that the FE model is very effective for predicting the microstructure, the phase transformation, the grain growth and the hardness.

2. One of the most practical methods for eliminating martensite formation during cooling of the welding is preheating. The proper selection of the preheat temperature is important in terms of time and cost. It was found that preheating the material to $225^{\circ} \mathrm{C}$ eliminates martensite formation completely for $12 \mathrm{~mm}$ thick, V-shaped butt welding of AISI 1045 steel.

3. The presented FE model can be used easily for different thicknesses and groove shapes to evaluate the quality of the welding process.

Acknowledgments: We thank the Scientific Research Projects (BAP) unit of Gaziantep University for supporting this study.

Author Contributions: O.E. supervised the whole study and participated the numerical simulations and experimental studies. A.S.A. carried out the finite element analyses and verification of the simulation results. K.G. designed and performed experimental works. N.F.Y. provided material data and analyzed the experimental findings.

Conflicts of Interest: The authors declare no conflict of interest.

\section{References}

1. Finite Element Method: An Introduction. Available online: faculty.ksu.edu.sa/rizwanbutt/Documents/ FiniteElementsmethods.pdf (accessed on 1 February 2017).

2. Sattari-Far, I.; Farahani, M.R. Effect of the weld groove shape and pass number on residual stresses in butt-welded pipes. Int. J. Press. Vessel. Pip. 2009, 11, 723-731. [CrossRef]

3. Barsoum, Z.; Lundbäck, A. Simplified FE welding simulation of fillet welds-3D effects on the formation residual stresses. Eng. Fail. Anal. 2009, 7, 2281-2289. [CrossRef]

4. Tsai, T.C.; Chou, C.C.; Tsai, D.M.; Chiang, K.T. Modeling and analyzing the effects of heat treatment on the characteristics of magnesium alloy joint welded by the tungsten-arc inert gas welding. Mater. Des. 2011, 8-9, 4187-4194. [CrossRef]

5. Garzon, C.M.; Giraldo, J.E. Numerical and experimental analysis of microstructure evolution during arc welding in armor plate steels. J. Mater. Process. Technol. 2009, 4, 1688-1700. 
6. Zhang, G.; Zhou, C.; Wang, Z.; Xue, F.; Zhao, Y.; Zhang, L. Numerical simulation of creep damage for low alloy steel welded joint Considering as-welding residual stress. Nucl. Eng. Des. 2012. [CrossRef]

7. International Standard Organization, for Welding Groove Shapes. Available online: http://www.iso.org (accessed on 2 February 2017).

8. DEFORM ${ }^{\mathrm{TM}}$ User's Manual V. 10.0, Released 2011. Available online: www.deform.com (accessed on 2 February 2017).

9. Vander Voort, G.F. Atlas of Time-Temperature Diagrams for Irons and Steels; ASM International: Cleveland, OH, USA, 1991.

10. ASM International Handbook Committee. ASM Handbook, Volume 04-Heat Treating; ASM International: Cleveland, OH, USA, 1991; pp. 12-22.

11. American Standard Test Material, ASTM Microstructure Preparation Standard, ASTM E3-11 2012. Available online: www.astm.org/Standards (accessed on 2 February 2017).

12. American Standard Test Material, ASTM Grain Size Measurement Technique, ASTM E112-13 2012. Available online: www.astm.org/Standards (accessed on 2 February 2017).

13. American Standard Test Material, ASTM Hardness Test, ASTM E18-16, 2012. Available online: www.astm. org/Standards (accessed on 2 February 2017).

(C) 2017 by the authors; licensee MDPI, Basel, Switzerland. This article is an open access article distributed under the terms and conditions of the Creative Commons Attribution (CC BY) license (http://creativecommons.org/licenses/by/4.0/). 